\title{
SOBRE A ESSÊNCIA E FORMA LÓGICA DA NORMA JURÍDICA NA TEORIA GERAL DO DIREITO CONTEMPORÂNEA
}

\author{
ON THE ESSENCE AND LOGICAL FORM OF LEGAL NORMS IN \\ CONTEMPORARY GENERAL THEORY OF LAW
}

RESUMO: O presente artigo tem por objeto as normas jurídicas, e por objetivo empreender uma análise destas, a fim de determinar a sua essência e forma lógica. Para tanto, principia-se por uma análise das relações entre Direito e norma, a fim de esclarecer o fundamento de validade das normas jurídicas e o papel que elas desempenham no interior do sistema jurídico. Essa análise conduz à problemática da própria essência das normas de direito, na medida em que a grande variabilidade de conteúdo das normas jurídicas exige a identificação de um elemento comum a perpassar todos os objetos que recebem tal qualificação. Considera-se, assim, a norma jurídica como sendo um "imperativo autorizante", cujo aspecto determinante é a bipolaridade que vincula dois sujeitos distintos e que faculta a exigência de certos comportamentos. Tal essência, por sua vez, se exprime em proposições cuja forma lógica específica também será examinada, sendo que tal forma lógica se apresenta como uma disjunção que une duas proposições condicionais, as quais, por sua vez, articulam em seus nexos implicativos proposições descritivas e prescritivas, isto é, fixam como consectários de certos fatos deveres correlativos. A fim de atingir os objetivos pretendidos, será adotado o método de abordagem dedutivo, e o procedimento de pesquisa bibliográfica, recorrendo-se a estudos e categorias teóricas já consagrados nos âmbitos da Teoria Geral do Direito e da Filosofia do Direito.

PALAVRAS CHAVE: Norma Jurídica, Essência, Forma Lógica, Validade.

ABSTRACT: The present paper aims at analyzing legal norms in order to determine their essence and logical form. To this purpose, it will engage in the analysis of the relationship between the totality of the legal system and legal norms individually considered, in order to clarify the source of validity of such norms and their role within the system itself. This analysis leads to the problem of the essence of legal norms, given that the variability of their content demands the recognition of a common element among all objects qualified as such. Thus, legal norms are considered to be "authorizing imperatives", having the determinant aspect of bipolarity, which links two different subjects and enables the demand for certain behaviors. This essence, in turn, can be expressed in propositions with a specific logical form that will also be examined, considering that such logical form presents itself as a disjunction that unites two conditional propositions, which, in their turn, articulate in their nexus descriptive and prescriptive propositions, that is, they establish as consequent of certain facts correlative duties. In order to attain the aforementioned objectives, it will be adopted the deductive method of

\footnotetext{
${ }^{1}$ Advogado. Mestrando em Direito pela Pontifícia Universidade Católica de São Paulo (Núcleo de Direito Constitucional, linha de Pesquisa: Efetividade do Direito e Limitações da Intervenção Estatal). Bacharel em Direito pela Universidade Presbiteriana Mackenzie. Graduando em Filosofia pela Universidade Federal de São Paulo.
} 
approach, and the procedure of bibliographical research, with the use of already established theoretical categories in the fields of General Theory of Law and Philosophy of Law.

KEYWORDS: Legal Norms, Essence, Logical Form, Validity.

\section{INTRODUÇÃO}

A norma jurídica é objeto de central interesse dos operadores e estudiosos do Direito, eis que é através dela que se operacionalizam as opções políticas e legislativas decorrentes do exercício do poder soberano do Estado.

Tanto na prática forense quanto nos textos jurídico-dogmáticos da doutrina as incontáveis referências aos termos "norma" e "norma jurídica" dão testemunho de tal circunstância, atestando, pois, o fato de que o Direito é, acima de tudo, um fenômeno de caráter normativo.

Nada obstante, um breve vislumbre do ordenamento jurídico brasileiro permite constatar que a realidade a que se atribui a denominação de "norma jurídica" alcança uma variedade significativamente ampla de objetos, havendo, pois, normas que disciplinam os mais variados segmentos da vida humana, com as mais diversas finalidades.

Ainda, os textos legais de onde são extraídas essas normas incorporam elementos dos mais diversos tipos de linguagem, fazendo alusões a questões de cunho político-filosófico, técnico-científico, sociológico, etc. De fato, conquanto, segundo Paulo de Barros Carvalho (2015), a linguagem do direito positivo seja uma linguagem técnica, também é verdadeiro que nela estão presentes termos da linguagem ordinária, científica, filosófica, e até artística. Basta considerar que o direito positivo abrange, por exemplo, desde a Constituição Federal até as regulamentações do Conselho Federal de Medicina e do Banco Central, cada qual com uma terminologia que lhe é própria.

Dada, assim, a importância da norma jurídica para todo e qualquer segmento do Direito, e dada, igualmente, a amplitude de objetos que ela alcança, é de enorme interesse para a compreensão da experiência jurídica a correta apreensão do que seja exatamente a norma.

Há, conforme ensina Maria Helena Diniz (2003), aspectos essenciais que perpassam todo o espectro quase interminável de objetos aos quais a alcunha "norma jurídica" se aplica.

Além disso, esses elementos essenciais podem ser reduzidos a uma forma lógica comum, que vem sendo analisada especialmente a partir de autores como Nikolai Korkunov (1909) e Hans Kelsen (2009), e que, no Brasil, recebeu dedicada atenção de autores como Lourival Vilanova (2010) e Paulo de Barros Carvalho (2015). 
Assim, com o isolamento da norma jurídica em seus aspectos essenciais, é possível não apenas apartar os usos corretos e incorretos dessa expressão, mas, sobretudo, compreender a relação que a norma jurídica estabelece com outros termos de inegável importância no discurso jurídico, tais quais "direitos", "deveres", "ordenamento jurídico", "proposição jurídica", "aplicação", "incidência", e muitos outros.

Tudo isso contribui para uma compreensão do Direito enquanto um sistema, cujas partes integrantes, que são as normas, se estruturam hierarquicamente de uma maneira determinada, comunicando validade umas às outras segundo um "esquema em árvore" que acaba por remeter ao ponto de partida da ordem jurídica e do próprio Estado.

No mais, a apreensão da norma jurídica também revela a maneira como se constituem as relações jurídicas, sobretudo porque a forma lógica a que a norma pode ser reduzida explicita a maneira como o Direito vincula circunstâncias da ordem do "ser" a consequências da ordem do "dever ser".

Esse fato, por sua vez, põe em evidência a circunstância de que direitos e deveres, enquanto facetas de uma mesma realidade que tem origem na norma, são criações da própria atividade humana que origina a norma jurídica.

Diante do que se expôs, fica claro o quanto o estudo da norma jurídica tem a contribuir para uma compreensão global e sistemática do direito, de sorte que a resposta às indagações "o que é a norma?" e "que forma ela tem?" em muito ultrapassa os limites desses dois questionamentos, fazendo emergir entendimentos mais precisos do fenômeno jurídico que alcançam o Direito como totalidade, em todas as suas áreas.

\section{DIREITO E NORMA}

Uma das maneiras tradicionais através da qual a filosofia e a teoria geral do Direito compreendem o seu próprio objeto de estudo consiste em equipará-lo ao conjunto de normas jurídicas dotadas de validade em um determinado Estado. ${ }^{2}$ Essa visão, muito embora coloque fora de seu alcance uma imensa gama de significados que o termo "direito" parece assumir no

\footnotetext{
${ }^{2}$ Esse posicionamento pode ser encontrado, por exemplo, já em Rudolf Von Ihering, que afirma: "A corrente definição de direito é a seguinte: direito é a totalidade das normas coativas válidas em um Estado, e em minha opinião ela atingiu com isso a verdade." (1913, p. 239-240, tradução nossa). Considerações semelhantes podem ser verificadas também em "A luta pelo direito", onde Ihering assinala: "A palavra 'direito' é empregada em sentido duplo, tanto objetivo quanto subjetivo. No sentido objetivo é o conjunto de leis fundamentais editadas pelo Estado, ou seja, o ordenamento jurídico da vida e, no sentido subjetivo, é a atuação concreta da norma abstrata no direito específico de determinada pessoa" (2013, p. 37).
} 
uso da linguagem comum, é metodologicamente útil, traduzindo aquilo que Maria Helena Diniz (2014, p. 55) denominou de "redução científica do direito à normatividade".

Com efeito, em sua "Teoria Pura do Direito", Kelsen faz uso dessa redução exatamente para conferir ao Direito a pureza metodológica de uma ciência propriamente dita. Em outras palavras, tal perspectiva tem por objetivo a delimitação de um método próprio para o estudo do Direito, o que, por sua vez, lhe garantiria teores de cientificidade. Assim, já no início da citada obra, Kelsen declara sua pretensão de "libertar a ciência jurídica de todos os elementos que lhe são estranhos", não porque se negue a relação do Direito com domínios como a sociologia e a psicologia, por exemplo, mas para "evitar um sincretismo metodológico que obscurece a essência da ciência jurídica e dilui os limites que lhe são impostos pela natureza de seu objeto" (2009, p. $1-2)$.

Com o fim de evitar, portanto, que o Direito se contamine não apenas com o exame de objetos, mas, sobretudo, com o emprego de métodos que não lhe pertencem, Kelsen (2009, p. 5) define-o como "uma ordem normativa da conduta humana, ou seja, um sistema de normas que regulam o comportamento humano". John Austin (2001, p. 19), em seu The province of jurisprudence determined, formula definição semelhante, assinalando que o agregado de normas estabelecidas pelo superior político, isto é, o soberano ou um subordinado com poderes delegados pelo primeiro, denomina-se propriamente "direito", ou ainda, "direito positivo". Desse modo, Austin indica um outro elemento que é de suma importância também para Kelsen, ainda que este o conceba de maneira inteiramente diversa: o fundamento de validade das normas jurídicas. Entretanto, o que interessa deixar assente, num primeiro momento, é que por meio da redução do direito à normatividade positiva as questões propriamente jurídicas se poderiam resolver, assim acreditava Kelsen, exclusivamente a partir de uma metodologia própria da Ciência do Direito, a saber: a interpretação normativa, e isso garantiria ao Direito o caráter de uma ciência - objetivo visado pela teoria pura.

A norma, consequentemente, operaria como um esquema de interpretação a partir do qual fatos que, em sua pureza empírica, seriam irrelevantes ao Direito, adquiririam um sentido próprio no âmbito de interesse jurídico, ou, como coloca Kelsen (2009, p. 4), adquiririam uma "particular significação jurídica". É assim, por exemplo, que o ato de dois indivíduos assinando uma folha de papel (fato empírico) adquire o sentido de ser a conclusão de um contrato (fato jurídico). Em outros termos, os fatos empíricos adquirem relevância jurídica somente na medida em que alguma norma jurídica positiva lhes empreste sentido. 
No entanto, se os fatos adquirem significação jurídica somente através da mediação da norma, e se uma norma jurídica, por seu turno, só pode extrair sua validade de uma outra norma que lhe seja superior, então é necessário que o fechamento do sistema seja dado por uma norma, e não por um fato. Com efeito, já no século XVIII David Hume identificou que um "dever ser" não pode ser deduzido de algo que é, isto é, de um "ser". ${ }^{3}$ Kelsen reconhece essa impossibilidade $^{4}$ e, mantendo em vista que a norma jurídica exprime um "dever ser", postula a necessidade de uma norma fundamental como fundamento de validade de todo o sistema (KELSEN, 2009, p. 217).

Há aqui, portanto, um aspecto que diferencia radicalmente a teoria do Direito de Kelsen daquelas de seus predecessores. De fato, embora autores como Ihering e Austin identificassem o Direito com o sistema de normas jurídicas positivadas por um determinado Estado, ambos indicavam fatos como o fundamento de validade último das normas. Consoante leciona Tércio Sampaio Ferraz Júnior (2014), no caso de Ihering, o centro nuclear da teoria é a noção de vontade, que permite identificar a impositividade do Direito a um "querer dotado de poder". A posição de Austin (2001) não é muito distante, visto que ele identifica a norma jurídica como um comando, e este, por sua vez, é a expressão de um desejo acompanhada do poder de infligir algum mal ao destinatário da ordem acaso esta não seja observada. A norma jurídica seria, desde esse ponto de vista, um comando oriundo da vontade do soberano, e sua validade decorreria dessa vontade associada ao poder de infligir um mal a quem a descumpre.

Kelsen recusa enfaticamente a possibilidade de situar o fundamento de validade de uma norma jurídica a partir da vontade, ainda que acompanhada de poder, daquele que a produz. A esse respeito, ele anota:

\footnotetext{
${ }^{3}$ Em seu "Tratado da Natureza Humana", David Hume estabelece aquela que ficou conhecida como "Lei de Hume", ao perceber a impossibilidade de se deduzir de um juízo sobre o ser um outro sobre o dever ser. Com efeito, o filósofo escocês registra: "Em todo sistema de moral que até hoje encontrei, sempre notei que o autor segue durante algum tempo o modo comum de raciocinar, estabelecendo a existência de Deus, ou fazendo observações a respeito dos assuntos humanos, quando, de repente, surpreendo-me ao ver que, em vez das cópulas proposicionais usuais, como é e não é, não encontro uma só proposição que não esteja conectada a outra por um 'deve' ou 'não deve'. Essa mudança é imperceptível, porém da maior importância. Pois, como esse 'deve' ou 'não deve' expressa uma nova relação ou afirmação, esta precisaria ser notada e explicada; ao mesmo tempo, seria preciso que se desse uma razão para algo que parece inteiramente inconcebível, ou seja, como essa nova relação pode ser deduzida de outras inteiramente diferentes" (2009, p. 509).

${ }^{4}$ Embora sem fazer referência a Hume, Kelsen, na "Teoria pura do direito", anota: "Ninguém pode negar que o enunciado: tal coisa é - ou seja, o enunciado através do qual descrevemos um ser fático - se distingue essencialmente do enunciado: algo deve ser - com o qual descrevemos uma norma - e que da circunstância de algo ser não se segue que algo deva ser, assim como da circunstância de que algo deve ser não se segue que algo seja" (2009, p. 6). Esse entendimento também pode ser encontrado em General theory of law and state, em que Kelsen assinala: "A razão para a validade de uma norma não é, como o teste de verdade de um enunciado sobre o 'ser', a sua conformidade com a realidade. A questão de por que alguma coisa deve ocorrer não pode jamais ser respondida por meio de uma asserção no sentido de que algo ocorre, mas apenas pela asserção de que algo deve ocorrer" (tradução nossa) (2005, p. 110).
} 
O fato de alguém ordenar seja o que for não é fundamento para considerar o respectivo comando como válido, quer dizer, para ver a respectiva norma como vinculante em relação aos seus destinatários. Apenas uma autoridade competente pode estabelecer normas válidas; e uma tal competência somente se pode apoiar sobre uma norma que confira poder para fixar normas. A esta norma se encontram sujeitos tanto a autoridade dotada de poder legislativo como os indivíduos que devem obediência às normas por ela fixadas" (KELSEN, 2009, p. 216-217).

Assim, com o propósito de conferir coerência lógica ao sistema jurídico, Kelsen rompe com uma tradição que se encontrava, ao menos em parte, presente já no "Leviatã", de Thomas Hobbes, e que consistia em situar o fundamento de validade das normas jurídicas na vontade do soberano (embora tenha havido grande divergência entre os signatários dessa tradição quanto a quem seria o depositário da soberania). ${ }^{5}$

De fato, a teoria de que o fundamento de validade das normas jurídicas provenha de algum modo da vontade, a que Tércio Sampaio Ferraz Júnior se refere como "Teoria Imperativista" (2014, p. 62), além de todos os problemas que este autor realça, insere como ponto de partida do sistema jurídico um elemento fático de caráter psicológico/político/sociológico (a depender de como se queira compreender tal vontade), o que na teoria de Kelsen é inaceitável, seja pelas dificuldades lógicas já assinaladas, seja também porque contamina a pureza metodológica do direito. Com efeito, se o fundamento das normas jurídicas retrocede, em última análise, a um componente de caráter não normativo, o método da interpretação normativa não pode dar conta de todo o sistema jurídico, e o sincretismo metodológico que Kelsen pretendia evitar tornar-se-ia inevitável. Consequentemente, torna-se necessária a introdução de uma norma fundamental e pressuposta, uma norma "cuja validade não pode ser derivada de uma norma superior", e que dá unidade ao sistema já que "todas as normas cuja validade pode ser reconduzida a uma mesma norma básica formam um sistema de normas, uma ordem" (tradução nossa) (2005, p. 111).

Por outro lado, soa, a princípio, inaceitável que os vários conteúdos de todas as normas jurídicas possam ser reconduzidos a uma única norma fundamental. Deveras, há uma pluralidade incomensurável de condutas imputadas por normas legais, e muitas delas sem nenhuma relação entre si, afora o fato de pertencerem a um mesmo sistema jurídico. Kelsen está consciente disso, e, por esse motivo, exclui da norma fundamental todo e qualquer conteúdo "material":

\footnotetext{
${ }^{5}$ Não obstante Hobbes mantivesse vínculos com a tradição jusnaturalista, referindo explicitamente a um "direito natural" (2014, p. 110), nele já se pode encontrar traços da orientação acima indicada, pois que o referido autor afirma, em uma das passagens de sua obra, que "todas as leis, escritas ou não, recebem toda a sua força e autoridade da vontade do Estado, isto é, da vontade do representante, que numa monarquia é o monarca e, em outros tipos de governo, a assembleia soberana" (2014, p. 214).
} 
A norma fundamental de uma ordem jurídica não é uma norma material que, por seu conteúdo ser havido como imediatamente evidente, seja pressuposta como a norma mais elevada da qual possam ser deduzidas - como o particular do geral - normas de conduta humana através de uma operação lógica $(2009$, p. 220).

Assim, consoante anota Richard Posner (2003), a teoria de Kelsen traz a necessidade de uma norma fundamental que estabeleça competências para criar normas subordinadas. Em outros termos, a norma fundamental outorga autoridade para a criação das normas positivas superiores de um sistema jurídico. Ela é, pois, a norma já pressuposta no ato constituinte que faz com que este seja objetivamente interpretado como fato criador de normas jurídicas. A norma fundamental, portanto, somente pode fornecer o fundamento de validade das normas sobre ela fundadas, e não o conteúdo de validade destas (KELSEN, 2009).

Novamente com apoio em Richard Posner (2003), cabe dizer que a norma fundamental em Kelsen é "transcendental", no sentido de que ela opera como condição de possibilidade de uma teoria do direito e do próprio sistema jurídico. Ou, como o próprio Kelsen anota:

A norma fundamental não é criada através de um procedimento legal por um órgão criador de leis. Ela não é - como é uma norma jurídica positiva - válida por ser criada de uma certa maneira por um ato jurídico, mas é válida porque se pressupõe que ela é valida; e se pressupõe que ela é válida porque sem essa pressuposição nenhum ato humano poderia ser interpretado como sendo um ato jurídico, especialmente como um ato criador de normas (tradução nossa) (2005, p. 116).

No entanto, o fato de que a norma fundamental não encerra um conteúdo material bifurca a ciência jurídica em uma teoria estática e uma teoria dinâmica. Assim, conforme anota Maria Helena Diniz (2014, p. 56), à parte estática do Direito incumbiria estudar o sistema de normas em "seu estado de repouso", o que, nas palavras da autora, equivale a "partir das normas de direito positivo e confrontá-las entre si, numa unidade coerente e sistemática, sob o enlace dedutivo de preceitos normativos e da norma básica, mostrando o uno (sistema) no múltiplo (pluralidade de normas)". ${ }^{6}$

\footnotetext{
${ }^{6}$ A questão do papel da lógica no direito e, mais especificamente, a possibilidade de sua utilização para efetuar operações dedutivas a partir de normas é uma com relação à qual Kelsen se debateu em mais de uma oportunidade, tendo defendido posições diversas ao longo de suas obras. Assim, em General theory of law and state, o autor em comento argumenta de modo a pressupor a possibilidade de se realizar operações lógicas a partir de normas quando, por exemplo, trata da possibilidade de "derivar" normas particulares de uma norma básica, tal como se deriva o particular a partir do geral $(2005$, p. 112). Na edição revisada da "Teoria pura do direito", Kelsen alterou esse ponto de vista ao perceber que as normas não possuem valor de verdade. Argumentou, então, que os princípios lógicos seriam aplicáveis apenas indiretamente às normas, já que as proposições jurídicas descritivas por meio das quais se pode declarar a validade de uma norma (isto é, a sua pertinência ao sistema) possuem valor de verdade e podem, por conseguinte, se submeter aos princípios lógicos. Posteriormente, em General theory of norms, Kelsen alterou novamente o seu posicionamento, passando a entender que mesmo as proposições jurídicas descritivas que asseveram a validade de normas estão sujeitas à carência de relações lógicas que subsiste nas normas descritas.
} 
A teoria dinâmica, por sua vez, enfoca o Direito em seu movimento interno, é dizer, considera-o pelos seus processos de produção e aplicação. Por esse prisma, a teoria jurídica não se pode reduzir a operações lógicas que reconduzam as normas mais particulares às mais gerais que lhe conferem validade, pois, como registrado, o ponto de partida, a norma fundamental pressuposta, não é uma norma material, ou seja, não encerra um conteúdo do qual sejam dedutíveis normas de conduta humana. A norma básica do sistema "meramente estabelece uma certa autoridade, a qual pode muito bem por sua vez investir de poder de criação normativa algumas outras autoridades" (tradução nossa) (KELSEN, 2005, p. 113). Assim, o conteúdo das normas jurídicas derivadas da norma fundamental só pode ser determinado através de atos levados a efeito pela autoridade a quem a norma fundamental outorga competência, ou de outras autoridades que recebam da primeira a competência para estabelecer normas positivas no sistema (KELSEN, 2009).

Em resumo, o sistema jurídico se penetra por um princípio estático e outro dinâmico, na medida em que a natureza da norma fundamental permite atos de criação, por meio dos quais são delegadas competências legislativas e originadas normas de conduta que ensejam deduções lógicas de normas mais específicas. Via de consequência, a recondução das normas de conduta mais particulares às mais gerais só retrocede, a partir de seu conteúdo, até certo ponto, momento em que esbarra no dinamismo do sistema, isto é, encontra limite num ato de criação normativa, este autorizado por uma norma superior, cujo fundamento de validade retrocede, em última análise, à norma fundamental. Consequentemente, o que confere unidade ao sistema de normas, na visão de Kelsen, é a validade das normas jurídicas, esta sim passível de recondução, mesmo das normas mais particulares, à norma fundamental.

Como resultado de todos os pontos examinados até aqui, segue-se um quadro geral que muito se aproxima da sintética descrição feita por Joseph Raz (2012, p. 139):

A organização e a estrutura de um sistema jurídico, de acordo com Kelsen, são representadas por um diagrama em árvore. O princípio ordenador do diagrama em árvore e a chave da estrutura do sistema jurídico é o conceito de cadeia de validade.

De se assinalar, ainda, que o sistema jurídico deve ter um mínimo de eficácia para que as suas normas tenham validade. Isso não equivale a dizer que o fundamento de validade do ordenamento jurídico seja a sua eficácia - pois que o fundamento de validade é a norma

Assim, por exemplo, asseverar a existência de normas que estabelecem deveres mutuamente excludentes não geraria contradição, que somente subsistiria acaso se afirmasse e se negasse a existência de uma mesma norma (1991, p. 223). Deve-se considerar, portanto, que a exposição feita no presente artigo é compatível com as posições defendidas por Kelsen anteriormente à obra General theory of norms, cuja publicação original data de 1979. 
fundamental -, mas significa que a eficácia social é condição para que o sistema possa valer. Kelsen exemplifica essa relação por meio do "silogismo normativo que fundamenta a validade de uma ordem jurídica" (2009, p. 236-237): a norma fundamental que enuncia que seus destinatários se devem conduzir de acordo com a Constituição efetivamente posta e eficaz equivale à premissa maior, e o juízo fático segundo o qual a Constituição foi efetivamente posta e é eficaz traduz a premissa menor, donde se segue, como conclusão, o juízo de "dever ser" concernente à necessária observância das normas do sistema jurídico.

Miguel Reale, ao analisar esse aspecto da teoria de Kelsen, observa que "um mínimo de eficácia é essencial ao conceito mesmo de normatividade", posto que a norma, enquanto esquema de interpretação, exige um objeto interpretável, "sendo óbvio que aquele deixaria de valer, de ter sentido, se nada houvesse a interpretar" (2002, p. 468).

Diante das considerações feitas até aqui, fica claro que a redução do Direito à normatividade, para usar, novamente, a expressão empregada por Maria Helena Diniz, permite delimitar com alguma precisão o objeto e a metodologia próprias da ciência jurídica, além de conceber a relação entre Direito e norma como aquela existente entre o todo e a parte. O Direito é, pois, nas palavras de Norberto Bobbio, "uma experiência normativa" (2010, p. 15). Por outro lado, essa concepção traz a dificuldade de se colocar o fundamento de validade do sistema, visto que, se o Direito é a totalidade de normas jurídicas positivas, e cada norma extrai sua validade de uma norma superior, emerge a indagação sobre o elemento que encabeçaria o sistema. As soluções para essa questão parecem se concentrar, sobretudo, em duas alternativas: a postulação, à maneira de Kelsen (2009), ou, analogamente, a constatação, à maneira de Hart, ${ }^{7}$ de uma norma fundamental pressuposta, fundamento da autoridade objetivamente reconhecida no ato constituinte que cria uma determinada ordem jurídica, ou então o reconhecimento de um fato livre de toda e qualquer determinação normativa (a vontade acompanhada de poder, por exemplo) como ponto de partida da ordem jurídica, tal como postulava Austin (2001).

Nada obstante, qualquer que seja a solução adotada para o problema do fundamento de validade da ordem jurídica, e quer se pretenda uma ciência jurídica pura, quer se aceite certo limite daquele sincretismo que Kelsen rejeita, é inegável a íntima relação que se estabelece entre Direito e norma, pois, desde a perspectiva aqui adotada, o Direito consiste num sistema escalonado de normas positivas minimamente eficazes. Daí que compreender o direito exige a

\footnotetext{
${ }^{7}$ A rule of recognition proposta por Hart desempenha em seu sistema um papel semelhante à norma fundamental de Kelsen, na medida em serve de fundamento último de validade para criação de normas jurídicas, relativamente ao qual é impossível retroceder a uma fundamentação mais elevada, e que, além disso, assume a forma de uma norma, muito embora sua constatação seja empírica, e não analítica (1994, p. 105-106).
} 
compreensão de seus elementos constitutivos, do que resulta a importância de se analisar detalhadamente a norma jurídica, a fim de esclarecer sua essência e forma.

\section{DA NORMA JURÍDICA}

Se a norma jurídica é, como se afirmou, elemento formador do sistema normativo a que pode ser reduzido o Direito Positivo, e se o que se pretende é empreender uma análise desse elemento, então se faz necessária a diferenciação da norma quanto ao domínio de objetos a que ela pertence. Afinal, a análise de um objeto impõe o isolamento deste para que possa ser estudado em suas propriedades particulares.

Dessa forma, buscar-se-á nos tópicos seguintes caracterizar a norma jurídica para o fim de se alcançar uma conceituação da mesma. Para tanto, a norma será considerada a partir da natureza cultural de que se reveste, buscando-se os seus elementos diferenciadores. Assim, serão levados em considerações os processos que dão origem às normas de direito, isto é, os aspectos determinantes de sua gênese, encarada tanto de um ponto de vista interno à teoria normativista como de uma perspectiva externa capaz de revelar os múltiplos aspectos envolvidos na formação das normas jurídicas. Além disso, buscar-se-á as características intrínsecas da norma para o fim de se obter uma definição que a capture em seus elementos essenciais. Com essa análise empreendida, será possível avançar para a obtenção de uma estrutura formal capaz de explicitar os elementos constitutivos da norma jurídica, exprimindo-se assim a forma lógica a que toda norma de direito se reduz.

\subsection{GÊNESE E ESSÊNCIA}

Maria Helena Diniz (2003), ao discorrer sobre o conceito de norma jurídica, esclarece que o que define uma norma jurídica enquanto tal não é o seu conteúdo, uma vez que esse conteúdo pode variar, sem que essa variabilidade comprometa a essência da norma. Com efeito, a norma é "como que um invólucro capaz de reter dentro de si os mais variados conteúdos", de modo que todas as normas jurídicas "têm em comum alguma coisa, que faz delas normas jurídicas" (DINIZ, 2003, p. 50).

Compete, assim, indagar e, na medida do possível, determinar essa essência que faz com que um determinado objeto possa ser corretamente qualificado como uma norma jurídica. Isso equivale, pois, a definir o aspecto comum à totalidade das normas do Direito Positivo. 
Do que se analisou até aqui, pode-se dizer, preliminarmente, que as normas jurídicas integram um sistema, cuja totalidade é o próprio Direito Positivo. No mais, tais normas pertencem a esse sistema pelo fato de que foram criadas segundo a forma estabelecida pela ordem jurídica e por um ato de uma autoridade com prerrogativa para tal, sendo que o fundamento do poder de criação normativa concedido a essa autoridade retrocede ao ato fundador da própria ordem jurídica, quer seja esse ato amparado por uma norma fundamental pressuposta, quer não.

Nesse sentido, vale ressaltar as colocações de Goffredo Telles Júnior (2014), para quem a noção de norma supõe sempre uma ordenação no interior da qual essa norma esteja incluída. Para o referido autor, "uma norma não é nunca um imperativo isolado" (2014, p. 277), mas deve, necessariamente, estar incluída numa ordenação.

Essas considerações, entretanto, ainda não fornecem uma definição inteiramente satisfatória. De fato, elas indicam algumas propriedades extrínsecas comuns às normas jurídicas, encaradas pela ótica de uma teoria geral do Direito de cunho normativista, mas não permitem dizer em que consistem essas normas, e qual a sua forma. Falta, portanto, esmiuçar em maior detalhe a norma jurídica por uma perspectiva externa ao sistema normativo, e destacar os aspectos intrínsecos à noção mesma de norma jurídica.

Para alcançar tais propósitos, um primeiro passo pode ser dado situando a norma jurídica dentro de uma categoria mais abrangente, que permita dizer que tipo de objeto a norma jurídica é. Esse, com efeito, o caminho perfilhado por Maria Helena Diniz, que, antes de indicar aquilo que entende por essência da norma jurídica, investiga a realidade ôntica desta, concluindo que:

a norma jurídica não é uma natureza corpórea, nem inorgânica, nem biológica, tampouco é psiquismo, não é um fato mental, nem pura ideia de valor [...]. Encontra-se no reino da cultura, uma vez que é elaborada por homens sob o estímulo de certas urgências e com o propósito de realizar certos fins, cujo cumprimento se considera como justo (2003, p. 47).

Tal entendimento é concordante com a posição de Miguel Reale (2002) e, de fato, exprime uma constatação dificilmente contestável: a de que as normas jurídicas são objetos culturais, ou seja, sintetizam valores e o mundo natural.

Essa constatação, entretanto, ainda demanda maiores esclarecimentos. Com efeito, além da indicação de que tipo de objeto a norma jurídica é, impõe-se a necessidade de se elucidar o seu elemento diferenciador: o que particulariza a norma jurídica enquanto objeto cultural. A resposta a essa indagação pode ser dada de diferentes maneiras. Primeiro, poder-se-ia atentar para o processo de gênese das normas jurídicas, isto é, aquilo que Miguel Reale chama de 
nomogênese jurídica, e que consiste no resultado culminante de um processo que integra elementos fáticos e axiológicos, e, mediante a interferência do poder, produz uma solução normativa. Nas palavras de Reale (2002, p. 551):

É, com efeito, através de um processo ao mesmo tempo axiológico e teleológico, que surge a norma de Direito, a qual se apresenta, formalmente, como esquema geral de opção pela conduta reconhecida de valor positivo e, como tal, preservada; ou então de valor negativo e, como tal, vedada.

Colocando-se em outros termos, a norma jurídica aparece, no modelo tridimensional proposto por Miguel Reale, como produto resultante de uma opção do poder diante de soluções normativas possíveis dadas pela incidência de valores determinados sobre fatos determinados.

Há, portanto, um ato de escolha levado a efeito por quem detém o poder, do qual resulta a "obrigatoriedade de uma dada via ou diretriz de ação dentre as múltiplas vias e diretrizes possíveis, no quadro das implicações fático-axiológicas próprias de cada conjuntura histórica" (REALE, 1992, p. 133).

Tal perspectiva, evidentemente, ultrapassa o campo de investigação de uma ótica normativista pura, como aquela de Kelsen, pois situa a norma jurídica no contexto ético e sociológico do qual ela emerge. Para Kelsen, a norma jurídica, tal como deve ser apreendida pelo jurista, é um esquema de interpretação cuja validade se deriva de uma norma fundamental pressuposta. Portanto, não caberia considerar os processos sociológicos e os valores éticos que subjazem ao surgimento de uma norma; bastaria reconduzi-la, segundo o modelo de cadeia de validade examinado, ao fundamento último da ordem jurídica.

Veja-se, portanto, que o processo de produção das normas jurídicas pode ser encarado de pontos de vistas diversos: do interior e do exterior do sistema jurídico. A se adotar o primeiro, a produção das normas deve ser analisada pelo método de interpretação normativa, e nada mais é do que um ato de uma autoridade competente, que segue a forma definida pela ordem jurídica, e cuja validade se deriva da norma fundamental pressuposta ou do poder de fato que estaria na origem da ordem jurídica vigorante. Essa análise da gênese normativa é a que se revestiria de cunho científico, por esgotar-se no método próprio da ciência jurídica. Observando-se, contudo, do exterior do sistema jurídico, a produção das normas obedece à estrutura tridimensional proposta por Reale, compondo elementos fáticos e axiológicos dos quais soluções normativas possíveis resultam, sendo uma delas escolhida por um ato mediador do poder e, consequentemente, vinculando seus destinatários. Essa análise ultrapassa o método da interpretação normativa, sendo, portanto, de cunho filosófico. 
Assim, a norma jurídica pode ser apreendida como um objeto cultural que resulta da integração de fatos e valores, mediados pelo fenômeno do poder. Tais objetos, por sua vez, compõem um sistema normativo e podem ser interpretados do interior desse mesmo sistema, isto é, do interior do próprio Direito e pelo método que lhe é próprio. Nesse caso, as normas são o produto de atos de autoridade amparados em normas superiores, que retrocedem ao ponto de partida da totalidade do sistema (norma fundamental ou poder de fato normativamente indeterminado). Essas duas abordagens se diferenciam, segundo Tércio Sampaio Ferraz Júnior (2016), pelo nível em que se colocam: a primeira, num nível ontológico, a segunda, no nível da teoria geral do direito.

Dada, contudo, a abrangência do conceito de objeto cultural, caberia indagar, ainda, que forma específica esse objeto assume, no caso específico da norma jurídica, a fim de chegar a uma definição satisfatória. Aqui, uma divergência pode ser observada.

Para Kelsen (2009), normas jurídicas e proposições jurídicas são coisas distintas, embora relacionadas. Nesse sentido, veja-se o que assinala Maria Helena Diniz (2014, p. 102-103):

para Kelsen, a norma de direito não é um enunciado acerca de um objeto de conhecimento, mas uma prescrição e, como tal, um imperativo; a estrutura lógica da norma, ou melhor, a proposição, é que é um enunciado ou um juízo que enlaça um comportamento humano, estabelecido como devido, com uma consequência jurídica que deve ser aplicada pelo órgão da comunidade.

Assim, a se aceitar o ponto de vista de Kelsen, torna-se necessária uma diferenciação entre as normas jurídicas, que exprimem comandos, permissões e atribuições de poder ou competência, das proposições jurídicas a que essas normas são redutíveis enquanto objeto do conhecimento da Ciência do Direito.

Em outros termos, a norma jurídica não teria, segundo Kelsen, um valor de verdade. Ela se exprime pela forma de um imperativo e, por esse motivo, não pode ser nem verdadeira, nem falsa. A proposição jurídica a que essa norma é, enquanto objeto de conhecimento, traduzível, é por sua vez uma relação de imputação constatada descritivamente, esta sim passível de veracidade ou falsidade. Consequentemente, a proposição jurídica formulada pela Ciência do Direito que afirma que "no Direito Positivo Brasileiro o crime de homicídio simples deve ser sancionado com pena de reclusão de seis a vinte anos" exprime uma relação condicional entre um fato "A" e uma consequência "B" imputada a esse fato, referindo-se, portanto, à circunstância empiricamente aferível de que uma norma no sistema jurídico imputa a um certo fato uma sanção determinada. Tal proposição tem, portanto, valor de verdade, eis que desempenha função meramente descritiva/declarativa: descreve a relação estabelecida por uma norma válida que liga 
um pressuposto a uma consequência. É dizer: ou é verdadeiro que o crime de homicídio se liga, por uma norma jurídica válida, à sanção acima referida, ou é falso.

Inversamente, a norma jurídica subjacente a essa proposição é o imperativo que prescreve a punição do crime de homicídio na maneira especificada, e que, por seu turno, não é nem verdadeiro, nem falso, mas exprime uma ordem dirigida a certos funcionários públicos para que apliquem uma sanção, uma vez satisfeitos os pressupostos inscritos no ordenamento jurídico. Trata-se, pois, de uma função de linguagem inteiramente diversa, pois tem caráter prescritivo, e não meramente descritivo.

Consoante ressalta Richard Posner (2003), a norma e, consequentemente, o "dever ser" na teoria de Kelsen não possui qualquer conteúdo moral. Não exprime nem tem a pretensão de exprimir o que é correto. Trata-se de um "dever ser" que assume duas funções linguísticas diferentes, a depender de estar situado no contexto de uma proposição jurídica oriunda da Ciência do Direito, ou numa norma jurídica propriamente dita. No primeiro caso, apenas expressa a consequência que, no quadro normativo vigente, se deve seguir da ocorrência de um determinado fato juridicamente relevante. Cuida-se, portanto, de uma cópula que imputa determinadas consequências a determinados fatos, descrevendo um nexo de imputação que se estabeleceu por força da vontade da autoridade legislativa competente. É o que o próprio Kelsen (2009, p. 87) ressalta:

\footnotetext{
Na proposição jurídica não se diz, como na lei natural, que, quando A é, B é, mas que, quando A é, B deve ser, mesmo quando B, porventura, efetivamente não seja. O ser o significado da cópula ou ligação dos elementos na proposição jurídica diferente do da ligação dos elementos na lei natural resulta da circunstância de a ligação na proposição jurídica ser produzida através de uma norma estabelecida pela autoridade jurídica - através de um ato de vontade, portanto -, enquanto que a ligação de causa e efeito, que na lei natural se afirma, é independente de qualquer intervenção dessa espécie.
}

Seguindo essa mesma linha, Maria Helena Diniz (2014) assinala que o "dever ser", enquanto cópula lógica das proposições jurídicas, é moral e politicamente neutro, e não se refere, portanto, ao valor intrínseco daquilo que, enquanto eticamente desejável, deveria ser, mas diz respeito à imputação axiologicamente neutra de um fato a outro.

Essa diferenciação entre norma jurídica e proposição jurídica é realizada por Kelsen (2009) sobretudo com o propósito de distinguir a ciência do direito de seu objeto. Com efeito, a ciência do direito faz uso das proposições jurídicas para descrever o Direito e as normas que o compõem. O Direito em si, por sua vez, prescreve regras de conduta através das normas jurídicas que a ciência jurídica apreende e realça por meio de proposições descritivas. 
Autores há, entretanto, que questionam se essa distinção entre norma e proposição jurídica possui alguma valia. Nesse sentido, Maria Helena Diniz ressalta a "crítica da teoria egológica" a essa distinção. Referida crítica tem como expoente o jurista argentino Carlos Cossio, para quem a distinção entre normas e proposições jurídicas é uma "pueril e superfula reduplicação da mesma coisa" (DINIZ, 2014, p. 99).

Com efeito, Cossio (1954) considera que a "normatividade das normas", sua essência, isto é, aquilo que as torna normas jurídicas, é precisamente o dever ser enquanto cópula lógica, vale dizer, enquanto imputação de uma consequência a um fato.

A resposta oferecida por Kelsen a essa crítica de Cossio (1952, p. 45) consiste em afirmar que:

As normas jurídicas como objeto da ciência do Direito são função das autoridades jurídicas competentes, ou, para dizer o mesmo, função da comunidade jurídica. As regras de direito (no sentido descritivo da palavra) são a função da ciência do Direito, enquanto ato de conhecimento. A significação dos atos pelos quais as autoridades jurídicas na qualidade de órgãos da comunidade jurídica criam as normas jurídicas, não é a de conhecer algo, senão a de regulamentar a conduta dos indivíduos subordinados ao Direito (tradução nossa).

Portanto, o motivo que leva Kelsen a diferenciar normas de proposições jurídicas reside no caráter meramente descritivo destas, que as torna objeto de conhecimento mas não meio de conformação das ações humanas. Há, pois, uma diferença entre o "dever ser" prescritivo das normas jurídicas e o "dever ser" enquanto imputação que as proposições jurídicas exprimem. Logo, se o propósito da edição de normas jurídicas pelas autoridades é regular a conduta dos destinatários, há que se considerar as normas como prescrições, e não apenas como enunciados condicionais declarativos dos nexos de imputação presentes no ordenamento jurídico.

A se considerar adequadamente as diferentes funções da linguagem, tal como as discerne Paulo Barros de Carvalho (2015), vem à tona a razão de ser da divisão operada por Kelsen. Com efeito, a linguagem das normas jurídicas é aquela que se poderia denominar de "Linguagem prescritiva de condutas", ao passo que a linguagem das proposições jurídicas insere-se no âmbito da "Linguagem descritiva ou declarativa".

Apoiando-se nesses pressupostos, torna-se visível a distinção de dois níveis de linguagem no discurso jurídico: um da linguagem-objeto do direito positivo, com função pragmática preponderantemente prescritiva, isto é, tendente a obtenção de uma obediência do destinatário, e um da sobrelinguagem da Ciência do Direito, que descreve aquela linguagem objeto e, portanto, exerce função prioritariamente informativa. 
Portanto, uma correta conceituação da norma jurídica exige que se a tome enquanto inserida no contexto do Direito Positivo, isto é, exige que se tome como referência o sentido específico que a norma assume enquanto elemento do ordenamento jurídico, e não o sentido das proposições jurídicas que a Ciência do Direito emprega para descrever as normas.

Assim, a prevalecer o entendimento kelseninano, as normas jurídicas assumem a forma de um "imperativo sancionador" (DINIZ, 2014, p. 109). Todavia, a questão está longe de ser totalmente consensual. Com efeito, tanto a qualificação da norma jurídica como um imperativo sancionador, quanto a descrição de sua estrutura enquanto juízo hipotético-condicional encontram críticas em alguns autores. Assim, por exemplo, Goffredo Telles Júnior (2014) e Maria Helena Diniz (2003) entendem que a norma jurídica é um "imperativo autorizante". Imperativo, porque prescreve as condutas que são devidas e aquelas que são proibidas. Autorizante, porque autoriza o lesado pela violação da regra de comportamento enunciada a exigir o seu cumprimento ou a reparação do mal decorrente daquela violação. Como consequência, a norma jurídica seria sempre bilateral, pois em todos os casos de sua aplicação haveria um destinatário do comportamento prescrito, e um destinatário da autorização que faculta exigir o cumprimento do dever ou a imposição da sanção. $\mathrm{O}$ elemento diferencial da norma jurídica seria, desde esse ponto de vista, o fato de facultar a um determinado indivíduo que exija coativamente o comportamento prescrito pela norma.

Miguel Reale (2002), por sua vez, aponta para a insuficiência do juízo hipotéticocondicional como forma à qual seriam redutíveis as normas jurídicas em geral. Para o referido autor, inúmeras normas presentes no ordenamento não são redutíveis a enunciados estruturados de acordo com a indigitada forma:

Na realidade, as regras que dispõem sobre a organização dos poderes do Estado, as que estruturam órgãos e distribuem competências e atribuições, bem como as que disciplinam a identificação, modificação e aplicação de outras normas não se apresentam como juízos hipotéticos: o que as caracteriza é a obrigação objetiva de algo que deve ser feito, sem que o dever enunciado fique subordinado à ocorrência de um fato previsto, do qual possam ou não resultar determinadas consequências. Ora, não havendo alternativa do cumprimento ou não da regra, não há que falar em hipoteticidade.

O que efetivamente caracteriza uma norma jurídica, de qualquer espécie, é o fato de ser uma estrutura proposicional enunciativa de uma forma de organização ou de conduta, que deve ser seguida de maneira objetiva e obrigatória (REALE, 2002, p. 95).

A questão, conforme se assinalou, não é totalmente pacífica. De fato, não parece impossível, à primeira vista, traduzir, mediante algum esforço, exemplos de disposições 
normativas aparentemente não hipotéticas em enunciados condicionais da forma proposta por Kelsen. Assim, por exemplo, o artigo 18, § $1^{\circ}$, da Constituição Federal de 1988 proclama: "Brasília é a Capital Federal". Tal enunciado poderia ser interpretado da seguinte maneira: "dada a instituição da República Federativa do Brasil, na forma da presente Constituição (antecedente "A"), Brasília deverá ser a Capital Federal (consequente "B").

Essas considerações ganham força acaso se considere, como faz Aurora Tomazini de Carvalho (2014), a norma jurídica como distinta do enunciado (suporte físico) no qual aquela se apoia, sendo a norma, pois, o produto de uma construção intelectual levada a efeito a partir dos elementos presentes no enunciado. Tomando-se esse ponto de partira, a ausência de uma hipótese, isto é, de um antecedente condicional, no texto legal que serve de suporte à norma não deve opor nenhuma dificuldade ao modelo proposto, porquanto a construção do sentido da norma realizada pelo intérprete suprirá tal omissão.

Portanto, em conclusão, pode-se dizer que as normas jurídicas são objetos culturais que, de um ponto de vista ontológico, constituem-se como produto de uma mediação do poder sobre as sínteses resultantes da incidência de valores sobre determinados fatos. De um ponto de vista do interior de uma teoria geral do direito de cunho normativista, as normas jurídicas são o produto da atividade efetuada por autoridades que possuem, na ordem jurídica vigente, competência para criá-las, sendo o poder dessas autoridades delegado também por normas, cujo fundamento de validade retrocede ao ponto de partida do sistema jurídico como um todo.

No mais, as normas jurídicas assumem a forma de imperativos, podendo-se concebê-las como "sancionadoras", acaso se adote a perspectiva de Kelsen, ou "autorizantes", desde o ponto de vista defendido por Goffredo Telles Júnior e Maria Helena Diniz. Tal diferença, como se acentuou, decorre do fato de que as consequências previstas nas normas não se operam automaticamente, mas apenas por iniciativa de alguém autorizado a exigir a aplicação daquelas. Tais imperativos, enquanto situados no nível de uma linguagem preponderantemente prescritiva, exprimem um "dever ser" dirigido à conformação das ações humanas. No entanto, enquanto linguagem-objeto da ciência do direito, as normas podem ser traduzidas em proposições jurídicas que as descrevem, mas, neste caso, o "dever ser" assumirá meramente a função de cópula lógica condicional, isto é, traduzirá descritivamente a relação de imputação que liga o fato antecedente ao seu consequente. Na proposição jurídica, portanto, a dimensão pragmática prescritiva da norma cede lugar a uma função meramente descritiva, tomando-se como objeto de descrição o próprio Direito Positivo. 


\subsection{FORMA LÓGICA}

Muito embora Kelsen tenha dado grande ênfase à ideia de que as normas de direito sejam redutíveis a juízos hipotéticos-condicionais, essa posição pode, como assevera Maria Helena Diniz (2014), ser encontrada já em obra do século XIX de autoria do jurista russo Nikolai Korkunov. Com efeito, em sua obra General Theory of Law, Korkunov (1909, p. 176) afirma: "normas jurídicas não são simples comandos, elas são ao mesmo tempo comandos condicionais" (tradução nossa, a partir da tradução inglesa). Mais adiante, o referido autor esclarece o que entende por "comandos condicionais", assinalando que cada norma jurídica, além de estipular uma regra, define as próprias condições de aplicação, de modo que se compõe essencialmente de dois elementos: uma hipótese ou suposição e uma disposição ou ordem. Assim, uma norma legal pode sempre ser expressa na forma: "se...então...".

Entretanto, como assinala Tércio Sampaio Ferraz Júnior (2014), a norma jurídica não pode ser traduzida em um enunciado condicional comum. Acaso se procedesse dessa maneira, obter-se-ia uma proposição molecular que liga formal ou contingentemente duas proposições atômicas descritivas, e não a estrutura lógica da norma mesma. Nesta está, pois, necessariamente presente um operador normativo ou deôntico:

podemos descrever logicamente a estrutura de uma norma como composta de $1^{\circ}$ ) um operador normativo; $2^{\circ}$ ) uma descrição de ação que é o seu argumento; $3^{\circ}$ ) uma descrição da condição da ação. O operador determina o caráter normativo: norma obrigatória ou proibitiva ou permissiva; a descrição da ação constitui o conteúdo da norma; e a condição da ação é a condição da sua aplicação (FERRAZ JÚNIOR, 2014, p. 74).

Algumas complementações são, ainda, necessárias. Com efeito, a relação de implicação entre o enunciado descritivo antecedente (suporte fático) e o enunciado prescritivo consequente é, ela mesma, dada pela norma jurídica, pois que, consoante assinala Lourival Vilanova (2010, p. 59): "é o Direito positivo que institui o relacionamento entre o descritor (hipótese) e o prescritor (tese)".

Como consequência, a formulação da norma jurídica por meio da vinculação de uma proposição descritiva a uma proposição normativa através do operador lógico condicional, com um operador deôntico incidindo apenas no interior da proposição consequente, insinuaria que esta (tese) é implicada material ou formalmente pela antecedente (hipótese). Não é esse, contudo, o caso, pois que "sem a norma vincular as duas proposições, elas estariam isoladas, ou ligadas por outros vínculos" (VILANOVA, 2010, p. 59). 
Assim, faz-se necessária a introdução do "functor dever-ser" como incidente sobre o nexo entre a hipótese e a tese, pois que tal nexo inexistiria sem que aquele operador unisse as duas proposições. Com efeito, o vínculo de implicação que se estabelece entre o antecedente descritivo e o consequente prescritivo é, também ele, dado pela norma jurídica, é dizer, é ele próprio um "dever ser". Desse modo, a forma lógica da norma jurídica, segundo Lorival Vilanova (2010, p. 59), pode ser formalizada da seguinte maneira: "D (p $\rightarrow$ q)", em que "D" é o "functor dever ser", isto é, o operador deôntico modalmente neutro incidente sobre a relação implicacional, "p" é a proposição descritiva antecedente, " $\rightarrow$ " é o operador de implicação (condicional) e "q" é a proposição prescritiva consequente que em sua estrutura interna comporta um dos operadores deônticos modalizados (permitido, obrigatório ou proibido).

Com isso, a forma lógica das normas jurídicas se exprime, em linguagem natural, da seguinte maneira: "deve ser que A implica B", sendo "A" uma proposição descritiva e "B" prescritiva (VILANOVA, 2010).

Veja-se que a forma acima não chega a rejeitar inteiramente o modelo clássico "se A é, B deve ser", porquanto o enlace implicacional entre um juízo sobre o "ser" e outro sobre o "dever ser" se mantém, com a diferença de que a própria relação de implicação entre um e outro juízo recebe a incidência de um operador deôntico modalmente neutro (o functor dever-ser), que Lourival Vilanova (2010) considera necessário para estabelecer o vínculo interproposicional entre hipótese e tese. Trata-se, portanto, de um desdobramento analítico dos elementos implícitos à formulação clássica.

Além disso, o consequente da norma jurídica também pode ser decomposto, de modo a tornar explícitos os seus elementos internos, isto é, tornar mais preciso o seu campo de irradiação semântica, realçando limites mais claros para os objetos passíveis de ocupar a posição sintática da tese, que ficam omitidos na descrição acima. Para tanto, convém, mais uma vez, fazer referência a Aurora Tomazini de Carvalho (2014, p. 296), que assim assinala:

A posição sintática implicante é denominada de hipótese $(\mathrm{H})$ ou antecedente e descreve um acontecimento de possível ocorrência (f). A posição implicada é denominada de consequente $(C)$, ou tese e estabelece uma relação $(R)$ entre dois sujeitos ( $\mathrm{S}^{\prime}$ e $\left.\mathrm{S}^{\prime \prime}\right)$, modalizada como obrigatória $(\mathrm{O})$, proibida $(\mathrm{V})$, ou permitida $(\mathrm{P})$, que deve ser cumprida por um e pode ser exigida por outro.

Portanto, o que se verifica, na proposição consequente que integra a norma jurídica, é uma relação entre dois ou mais sujeitos (mas nunca de um sujeito com ele mesmo). Além disso, consoante lição de Lourival Vilanova (2000), a relação que se insere na posição sintática de consequente tem estrutura interna deôntica, de modo que, ocorrido o fato abstratamente 
estipulado na proposição antecedente (hipótese), deve sobrevir uma relação entre sujeitos, de tal modo que entre eles se instaurem, reciprocamente, como proibidas, obrigatórias ou permitidas, condutas determinadas.

Sintetizando os aspectos analisados até aqui, pode-se dizer que a norma jurídica compõese de uma proposição condicional que reúne uma proposição descritiva antecedente (hipótese) e uma proposição prescritiva consequente (tese), esta decomponível numa relação entre sujeitos dotada de estrutura interna deôntica, isto é, modalizada como obrigatória, proibida ou permitida. No mais, o nexo implicacional que une as duas proposições está no escopo de um operador modal neutro, a que Lourival Vilanova (2000) se refere como "functor D", o qual afeta todo o complexo proposicional normativo.

Esta descrição, entretanto, só dá conta de uma parte da norma jurídica, pois que não leva em consideração as consequências que sobrevêm ao descumprimento da prescrição prevista na proposição consequente. Trata-se, portanto, de uma análise parcial que toma como objeto apenas a norma primária, competindo, assim, complementá-la com uma análise da norma secundária. ${ }^{8}$

De fato, a norma secundária condiciona a aplicação de uma sanção ao não cumprimento do que a norma primária, na proposição consequente que a integra, estabelece como devido. Dessa forma, sua estrutura é semelhante à da norma primária, com a diferença de que a proposição assumida como hipótese é precisamente a não ocorrência do que a norma primária prescreveu.

Integrando-se a norma primária à secundária, chega-se à norma jurídica completa, cuja estrutura, conforme Aurora Tomazini de Carvalho (2014), pode ser simbolizada da seguinte maneira: "D $\left[(\mathrm{H} \rightarrow \mathrm{C}) \vee\left(\mathrm{H}^{\prime} \rightarrow \mathrm{S}\right)\right]$ ". Isto é: deve ser que a hipótese "H" implique a Consequência "C" (sendo esta uma relação entre sujeitos modalizada como obrigatória permitida ou proibida), ou que a hipótese "H'" (inocorrência de conduta prescrita pela norma primária) implique a sanção "S" mediante o exercício da coação estatal.

\section{CONCLUSÃO}

\footnotetext{
${ }^{8}$ Convém deixar registrado que a distinção entre norma primária e secundária feita no presente trabalho não segue o modelo defendido por Kelsen na primeira edição da "Teoria Pura do Direito". Com efeito, Kelsen havia defendido a tese de que a norma primária seria aquela que estabelece a sanção, haja vista que a sanção seria condição para que uma conduta tivesse alguma consequência jurídica, sendo portanto o elemento decisivo na distinção das normas jurídicas das normas morais (1953, p. 66-68). Na segunda edição da obra, Kelsen abandona a referida distinção, passando a referir-se a normas jurídicas autônomas e não-autônomas (2009, p. 60-65). A distinção que adotamos entre norma primária e norma secundária segue, portanto, a posição de Lourival Vilanova (2010, p. 73-74).
} 
Em conclusão, cabe dizer que o Direito, enquanto objeto da ciência jurídica, pode ser apreciado como um sistema de normas jurídicas válidas num determinado Estado. Consequentemente, a norma jurídica é elemento constitutivo do Direito, que mantém com ele a relação que a parte mantém com o todo.

Tal constatação realça a importância de um exame detido da norma jurídica como pressuposto incontornável para a compreensão do próprio Direito.

Assim, pela "Teoria Pura" de Kelsen, a norma jurídica deve ser apreendida enquanto esquema de interpretação que traduz os fatos juridicamente relevantes, emprestando-lhes relevância jurídica e lhes prescrevendo uma determinada consequência. Desde essa perspectiva, a norma resulta da criação de autoridades competentes, as quais selecionam os fatos e as consequências a lhes serem atribuídas, sendo a autoridade reconhecida nas figuras criadoras do direito decorrente de normas cuja validade é assegurada por cadeias de validade que retrocedem a uma norma fundamental pressuposta, a qual é o ponto de partida de todo o sistema normativo.

Por outro lado, a realidade ôntica da norma se situa no plano dos objetos culturais, dentre os quais a norma se diferencia por resultar de processos de nomogênese jurídica, os quais integram fatos e valores, destes emergindo soluções normativas possíveis, das quais uma é escolhida pela mediação do poder.

No mais, a norma assume a forma de um imperativo direcionado à conformar as ações humanas. Esse imperativo, segundo Kelsen, tem a natureza de um imperativo sancionador, pois determina que os funcionários do Estado apliquem determinada sanção uma vez ocorrido o pressuposto fático de aplicação da norma. Essa concepção, entretanto, é objeto de críticas, sendo que Maria Helena Diniz e Goffredo Telles Júnior entendem que a norma jurídica é, na realidade, um imperativo autorizante, que traz a bilateralidade como elemento subjacente e necessário. Com efeito, a sanção não se opera imediata e automaticamente, mas apenas mediante provocação de quem é autorizado a reclamá-la. Daí o caráter autorizante inerente a toda e qualquer norma jurídica.

Quanto à sua forma, a norma jurídica, de um modo geral, é redutível a uma proposição condicional cujo nexo de implicação lógica interliga um enunciado descritivo e outro prescritivo ("se A é, B deve ser").

Essa formulação, contudo, oculta o fato de que o próprio vínculo implicacional entre o antecedente descritivo e o consequente prescritivo tem caráter deôntico, é dizer, a proposição prescritiva decorre do antecedente descritivo porque o Direito assim estabelece, e não porque 
haja um nexo formalmente necessário ou empiricamente dado nos fatos aos quais as proposições se referem.

Consequentemente, a formalização correta da proposição que exprime uma norma jurídica é "D ( $\rightarrow$ q)", em que "D" simboliza aquilo que Lourival Vilanova (2010) chama de "functor dever ser", isto é, o operador deôntico modalmente neutro incidente sobre a relação implicacional; "p" designa a proposição descritiva antecedente; " $\rightarrow$ " é o operador de implicação (condicional); e "q" é a proposição prescritiva consequente, que em sua estrutura interna comporta um operador deôntico modalizado (permitido, obrigatório ou proibido). ${ }^{9}$

Esse esquema, contudo, dá conta apenas da chamada "norma primária", a qual estatui direitos e deveres como decorrentes de determinados fatos, mas não prevê a sanção que se deve seguir alternativamente, acaso não observada a prescrição. Para alcançar a norma jurídica completa, portanto, faz-se necessário integrar a norma primária com a secundária, isto é, com a norma que condiciona uma sanção à inobservância do conteúdo prescritivo da norma primária. Logo, chega-se a uma disjunção, cuja estrutura lógica pode ser formalizada da seguinte maneira: "D $\left[(\mathrm{H} \rightarrow \mathrm{C}) \vee\left(\mathrm{H}^{\prime} \rightarrow \mathrm{S}\right)\right]$ ", fórmula esta que pode ser lida assim: "deve ser que a hipótese $\mathrm{H}$ implique o consequente $\mathrm{C}$, ou a hipótese $\mathrm{H}^{\prime}$ implique a sanção $\mathrm{S}$ ". Cabe atentar, aqui, que a consequência da norma primária é uma relação entre dois ou mais sujeitos, a qual tem estrutura interna deôntica: comporta condutas recíprocas qualificadas como obrigatórias, proibidas ou permitidas. Além disso, a hipótese $\mathrm{H}^{\prime}$, antecedente da norma secundária, consiste na inobservância da consequência estipulada na norma primária, sendo o consequente da norma secundária uma sanção a ser exercida através da coação estatal.

Logo, o Direito se compõe de normas que estabelecem como devidos certos nexos de implicação entre enunciados relativos ao "ser" e ao "dever ser", de tal modo que é por força do próprio Direito, isto é, do próprio sistema de normas, que a relação entre fatos e deveres se constitui. Dos fatos em si não decorre nenhum dever, donde que proposições do tipo "se A é, B deve ser", só podem exprimir uma relação condicional nos quadros de uma ordem normativa vigente e minimamente eficaz que imponha, como devido, o vínculo implicacional entre o enunciado antecedente e o consequente. Os deveres jurídicos, portanto, e os direitos que lhes são correlatos, são um produto das normas, e só através delas podem subsistir.

\footnotetext{
${ }^{9}$ Lembre-se, por oportuno, que os operadores modais são três, e apenas três: permitido, obrigatório e proibido, e que estes são intercambiáveis, isto é, podem ser reformulados com o uso de um dos outros dois operadores, eis que, por exemplo, afirmar que "p é obrigatório" equivale a dizer "não-p não é permitido" ou "não-p é proibido" (NAVARRO; RODRÍGUEZ; 2014, p. 20).
} 


\section{REFERÊNCIAS BIBLIOGRÁFICAS}

AUSTIN, John. The province o jurisprudence determined. Nova York: Cambridge University Press, 2001.

BOBBIO, Norberto. Teoria geral do direito. Tradução de Denise Agostinetti. 3. ed. São Paulo: Martins Fontes, 2010.

CARVAlHO, Aurora Tomazini de. Curso de teoria geral do direito: o constructivismo lógico-semântico. São Paulo: Noeses, 2014.

CARVALHO, Paulo Barros de. Direito Tributário: linguagem e método. São Paulo: Noeses, 2015.

COSSIO, Carlos. Teoria de la verdad jurídica. Buenos Aires: Editorial Losada, 1954.

COSSIO, Carlos; KELSEN, Hans. Problemas escogidos de la teoria pura del derecho: teoria egologica y teoria pura. Buenos Aires: Editorial Guillermo Kraft, 1952.

DINIZ, Maria Helena. A ciênica jurídica. 8. ed. São Paulo: Saraiva, 2014.

DINIZ, Maria Helena. Conceito de norma jurídica como problema de essência. 4. ed. São Paulo: Saraiva, 2003.

FERRAZ JÚNIOR, Tércio Sampaio. A ciência do Direito. 3. ed. São Paulo: Atlas, 2014.

FERRAZ JÚNIOR, Tércio Sampaio. Teoria da norma jurídica: ensaio de pragmática da comunicação normativa. 5. ed. São Paulo: Atlas, 2016.

HART, Herbert Lionel Adolphus. The concept of law. 2. ed. Nova York: Oxford University Press, 1994.

HOBBES, Thomas. Leviatã. Tradução de Rosina D'Angina. São Paulo: Martin Claret, 2014.

HUME, David. Tratado da natureza humana. Tradução de Débora Danowski. 2. ed. São Paulo: Editora Unesp, 2009.

IHERING, Rudolf Von. A luta pelo direito. 8. ed. Tradução de J. Cretella Jr. e Agnes Cretella. São Paulo: Editora Revista dos Tribunais, 2014.

IHERING, Rudolf Von. Law as a means to an end. Tradução de Isaac Husik. Boston: The Boston Book Company, 1913.

KELSEN, Hans. General theory of law and state. New Brunswick: Transaction Publishers, 2005

KELSEN, Hans. General theory of norms. Tradução de Michael Hartney. Nova York: Oxford University Press, 1991. 
KELSEN, Hans. Teoria Pura do Direito. Tradução de João Baptista Machado. 8. ed. São Paulo: Editora WMF Martins Fontes, 2009.

KELSEN, Hans. Théorie pure du droit. Tradução de Henri Thévenaz. Neuchâtel: Éditions de La Baconnière, 1953.

KORKUNOV, Nikolai Mikhailovich. General Theory of Law. Tradução de W.G. Hastings. Brookline (MS): Boston Book Company, 1909.

NAVARRO. Pablo E.; RODRÍGUEZ, Jorge L. Deontic logic and legal systems. Nova York: Cambridge University Press, 2014.

POSNER, Richard. Law, pragmatism and democracy. Cambridge: Harvard University Press, 2003.

RAZ, Joseph. O conceito de sistema jurídico: uma introdução à teoria dos sistemas jurídicos. tradução Maria Cecília Almeida. São Paulo: Editora WMF Martins Fontes, 2012.

REALE, Miguel. Filosofia do Direito. 20. ed. São Paulo: Saraiva, 2002.

REALE, Miguel. Lições preliminares de direito. 27. ed. São Paulo: Saraiva, 2002.

REALE, Miguel. O direito como experiência: introdução à epistemologia jurídica. 2. ed. São Paulo: Saraiva, 1992.

TELLES JUNIOR, Goffredo. Direito Quântico: ensaio sobre o fundamento da ordem jurídica. 9. ed. São Paulo: Saraiva, 2014.

VILANOVA, Lourival. As estruturas lógicas e o sistema de direito positivo. 4. ed. São Paulo: Noeses, 2010.

VILANOVA, Lourival. Causalidade e Relação no direito. 4. ed. rev. atual. ampl. São Paulo: Editora Revista dos Tribunais, 2000. 